\title{
Enhanced phagocytosis of Aggregatibacter actinomycetemcomitans cells by macrophages activated by a probiotic Lactobacillus strain
}

\author{
N. Jaffar, ${ }^{*}$ T. Okinaga, $\dagger$ T. Nishihara, $\dagger$ and T. Maeda ${ }^{1}$ \\ *Faculty of Health Sciences, Gong Badak Campus, Universiti Sultan Zainal Abidin (UniSZA), Kuala Terengganu, Terengganu Darul Iman, \\ 21300, Malaysia \\ †School of Oral Health Sciences, Faculty of Dentistry, Kyushu Dental University, Kitakyushu, 803-8580, Japan \\ ‡Department of Biological Functions Engineering, Graduate School of Life Science and Systems Engineering, Kyushu Institute of Technology, \\ Kitakyushu, 808-0196, Japan
}

\section{ABSTRACT}

The activation of phagocytosis is one important approach to clearing pathogenic cells in a host. This study evaluated the ability of probiotic lactobacilli to induce phagocytic activity as well as the clearance of a periodontal pathogen, Aggregatibacter actinomycetemcomitans. First, the activation of phagocytosis was found by using lyophilized dead cells. Probiotic Lactobacillus strains significantly enhanced the phagocytic activity of macrophage cells, indicating that the probiotic lactobacilli have a remarkable ability to stimulate the macrophages. Essentially, 3 Lactobacillus strains tested did not have any critical toxic effect on the murine macrophage, and Lactobacillus johnsonii NBRC 13952 showed the least cytotoxic effect on the RAW264.7 macrophages. The expression of classically activated macrophage markers, IL-1 $\beta$, and cluster of differentiation 80 increased by L. johnsonii NBRC 13952; however, there was no significant difference for IL-18. The highest phagocytic activity by macrophages was found in a condition in which the macrophage activated by $L$. johnsonii NBRC 13952 functions to kill the cells of $A$. actinomycetemcomitans. Correlating with the result, a high amount of hypodiploid DNA (SubG1) was detected from the macrophage cells stimulated by $L$. johnsonii NBRC 13952. Taken together, the results suggest that macrophages activated by the Lactobacillus strain can facilitate the phagocytosis of $A$. actinomycetemcomitans cells by linking with enhanced apoptotic activities. In conclusion, L. johnsonii NBRC 13952 has a certain role in activating the RAW264.7 macrophages, thereby counteracting the infection of $A$. actinomycetemcomitans.

Key words: phagocytosis, probiotic, periodontal pathogen, macrophage activation, apoptosis

Received December 26, 2017.

Accepted February 23, 2018.

${ }^{1}$ Corresponding author: toshi.maeda@life.kyutech.ac.jp

\section{INTRODUCTION}

Macrophages are key phagocytes in the innate immune response against invading microorganisms and play a significant role in the modulation of an inflammatory environment in the tissues (DeLeo, 2004). The response is influenced by the local microenvironmental signals (Murray and Wynn, 2011). In general the initial responder, macrophages usually trigger an inflammatory response and produce proinflammatory mediators such as tumor necrosis factor (TNF), IL-1, IL-6, IL-18, and IL-12 (Cohen, 2002). The response promotes the production of various antimicrobial factors and nitrogen intermediates that are highly toxic to kill infecting microorganisms (Murray and Wynn, 2011). However, excessive or prolonged macrophage activity for the bacterial clearance may trigger damage of the neighboring tissues at the infected site (Benoit et al., 2007). Finally, normal cell tissues are damaged through excessive responses by immune cells (Silva et al., 2015). Pathogens such as Aggregatibacter actinomycetemcomitans might be able to alter the modulation of leukocytic apoptosis or the cell death of macrophages by which the host immune response may be adversely influenced (Meyer et al., 1996; DeLeo, 2004). Basically, a normal treating process for the bacterial infection is the phagocytic activity and neutrophil apoptosis to kill the infecting bacteria, and then the apoptotic neutrophil cells are removed by macrophages (DeLeo, 2004). However, the normal pathway might be altered by the pathogens, which can use several survival strategies such as escaping the phagosome, inducing the lysis of neutrophil cells, and delaying the process of apoptosis to promote the propagation of intracellular pathogens (Meyer et al., 1996; DeLeo, 2004). A previous study reported the survival of internalized A. actinomycetemcomitans cells inside the murine macrophage in the infection model by confocal scanning microscopy (Kato et al., 1995). This activity halts the cell cycle at the $\mathrm{G}_{1}$ phase through the suppression of p21 expressed and the degradation of cy- 
clin D1, resulting in the induction of apoptotic cell death (Kasai et al., 2010; Okinaga et al., 2013). In addition, the biofilm of $A$. actinomycetemcomitans increased in a porous-type hydroxyapatite (HA) rather than a densetype HA, although biofilm dispersal was observed with time (Jaffar et al., 2016b). The property of porous-type $\mathrm{HA}$ is similar to dentin, and the property of dense-type HA is similar to enamel in the tooth (Sakaguchi and Powers, 2012). The biofilm formed at the dentinal tubule may cause the invasion of pathogenic cells through the root of the dentinal tubule or pulp cavity ( $\mathrm{Li}$ et al., 2000). Therefore, an alternative approach via the use of probiotic bacteria may be promising to combat the pathogenic strain, as the mature biofilm of $\mathrm{A}$. $a c$ tinomycetemcomitans cells was degraded by probiotic bacteria (Jaffar et al., 2016a). The approach has several advantages due to the effect of probiotic strains, which are able to modulate the immune response (Oelschlaeger, 2010; Jang et al., 2013, 2014; Ji et al., 2013). The macrophage cells might be activated by lactobacilli, which stimulate the production of both inflammatory

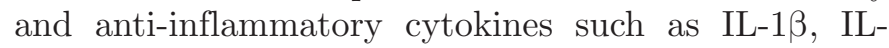
6, IL-12, IL-10, and TNF- $\alpha$ (Morita et al., 2002; Ji et al., 2013). However, to the best of our knowledge, there are so far no reports on the relationships between immune response, probiotic bacteria, and pathogenic bacteria. In this study we evaluated phagocytic activity by macrophage cells using the murine macrophage cell line RAW264.7 as an immune cell, lactobacilli as probiotic bacteria, and A. actinomycetemcomitans as a pathogen. In particular, we determined the efficiency of lactobacilli-activated macrophages in the presence or absence of $A$. actinomycetemcomitans.

\section{MATERIALS AND METHODS}

\section{Cell Culture}

The murine macrophage cell line RAW264.7 was grown in $\alpha$-minimum essential medium ( $\alpha$-MEM; Gibco Laboratories, Grand Island, NY) supplemented with $5 \%$ fetal bovine serum, penicillin G $(100 \mathrm{U} /$ $\mathrm{mL})$, and streptomycin $(100 \mu \mathrm{g} / \mathrm{mL})$ at $37^{\circ} \mathrm{C}$ inside a $5 \%$-controlled $\mathrm{CO}_{2}$ incubator.

\section{Bacterial Strains and Culture Conditions}

Aggregatibacter actinomycetemcomitans strain Y4 was obtained from Kyushu Dental University, Japan, and routinely grown in brain-heart infusion medium (Difco Laboratories, Detroit, MI) supplemented with $1 \%$ yeast extract (wt/vol) by shaking at $120 \mathrm{rpm}$ at $37^{\circ} \mathrm{C}$ and $5 \% \mathrm{CO}_{2}$ for $48 \mathrm{~h}$. In addition, probiotic bacteria Lactobacillus johnsonii NBRC 13952, Lactobacillus plantarum NBRC 15891, and Lactobacillus fermentum NBRC 15885 were obtained from Kitakyushu College of Technology, Japan. All probiotic bacteria were grown in De Man, Rogosa and Sharpe medium supplemented with $1 \mathrm{~mL} / \mathrm{L}$ of Tween 80 (Fluka, Sigma-Aldrich, St. Louis, MO) under anaerobic conditions at $37^{\circ} \mathrm{C}$ for 48 h.

\section{Preparation of Lyophilized Dead Bacterial Cells}

Overnight cultures of A. actinomycetemcomitans Y4 and probiotic lactobacilli were centrifuged at 12,063 $\times$ $g$ for $10 \mathrm{~min}$. Each cell pellet was collected and washed twice using autoclaved distilled water, and the pellet suspension was adjusted to a cell concentration of 2 $\times 10^{10}$ cells $/ \mathrm{mL}$ and autoclaved at $120^{\circ} \mathrm{C}$ for $15 \mathrm{~min}$. Last, all samples were lyophilized using a freeze dryer (Labconco, Kansas City, MO), and the powder forms were preserved at $-20^{\circ} \mathrm{C}$ for further experiments.

\section{Screening of Phagocytosis Activity}

The phagocytic activity of macrophages was determined using a phagocytosis assay kit (Cayman Chemical Co., Ann Arbor, MI). The RAW264.7 cells were cultured in tissue-culture sets $\left(1 \times 10^{6} \mathrm{cell} / \mathrm{mL}\right)$, seeded in 6-well plates (Corning Inc., Corning, NY) at a concentration of $4 \times 10^{5} \mathrm{cell} / \mathrm{mL}$, and incubated at $37^{\circ} \mathrm{C}$ and $5 \% \mathrm{CO}_{2}$. Each pellet suspension $(2 \mathrm{~mL})$ of dead cells of A. actinomycetemcomitans $\mathrm{Y} 4$ or probiotic bacteria, L. johnsonii NBRC 13952, L. plantarum NBRC 15891, and L. fermentum NBRC 15885 was mixed with the cell suspension of RAW264.7 macrophages to make a mixture at the multiplicity of infection (MOI) of 1,000:1 (bacterial cells:macrophage cells) in $\alpha$-MEM. A sample without any bacterial suspension was used as a negative control. All the samples were incubated for 24 $\mathrm{h}$ at $37^{\circ} \mathrm{C}$ and $5 \% \mathrm{CO}_{2}$. The determination of phagocytic activity was performed using an assay reagent, latex bead-rabbit IgG-fluorescein isothiocyanate (FITC; Cayman Chemical Co.). Initially, the latex beads were diluted 40 times using $\alpha$-MEM, and the diluted reagent (with beads) was replaced with the supernatant of the above mixture (after $24 \mathrm{~h}$ ) and incubated at $37^{\circ} \mathrm{C}$ for $2 \mathrm{~h}$ in the $5 \% \mathrm{CO}_{2}$ incubator. The IgG molecules bind with a protective protein and fragment crystallizable receptor on the surface of the activated macrophage cells; thereby, the uptake of the beads was facilitated. Thus, the presence of beads inside the macrophage cells was determined as the phagocytic activity by detecting the fluorescence at $498 \mathrm{~nm}$ of the excitation wavelength and at $522 \mathrm{~nm}$ of the fluorescence wavelength. The number of activated macrophage cells with the beads was counted using the All-in-One fluorescence micro- 
scope system (Keyence, Tokyo, Japan). The percentage of phagocytic activity was determined by calculating the ratio of the total number of fluorescence macrophages to the total number of all macrophages.

\section{Cell Viability}

The cytotoxic effect of bacterial cells against the RAW264.7 macrophage was determined using the trypan blue exclusion method. Briefly, the overnight culture of bacterial cells was centrifuged at 3,000 $\times$ $g$ for $10 \mathrm{~min}$ and suspended in $\alpha$-MEM. The ratio of bacterial cells and macrophage cells was adjusted to MOI values of 500:1, 50:1, and 5:1 before coincubation for $2 \mathrm{~h}$ at $5 \% \mathrm{CO}_{2}$. Subsequently, the mixed cells were washed thrice with $\alpha$-MEM supplemented with $200 \mu \mathrm{g} /$ $\mathrm{mL}$ of gentamycin to kill all the bacterial cells outside the macrophage cells and incubated in $2 \mathrm{~mL}$ of antibiotic-free $\alpha$-MEM for an additional $18 \mathrm{~h}$ at $37^{\circ} \mathrm{C}$ and $5 \%$ $\mathrm{CO}_{2}$. The viability of the macrophages was determined by counting the number of viable cells (using a hemocytometer) after being stained with $0.4 \%$ trypan blue dye (Nacalai Tesque, Kyoto, Japan). In addition, the effect of bacterial cells against the RAW264.7 cells was investigated using a fluorescence label method using a cytotoxicity assay kit for mammalian cells (Thermo Fisher, Waltham. MA). The total number of bacteria cells was determined using an automated microscopic counting system for fluorescence-labeled cells in which green-stained macrophage cells were viable and redstained cells were dead. The total number of viable macrophages after the coincubation with bacterial cells (A. actinomycetemcomitans Y4 or each probiotic bacterium; treated) was compared with that without any bacterial cells (untreated); thereby, the cell viability was displayed as the ratio of treated macrophage cells to untreated ones.

\section{Flow Cytometry to Analyze the Expression of CD80 Molecule}

The RAW264.7 macrophages were coincubated with L. johnsonii NBRC 13952 at the MOI 1:5 at $37^{\circ} \mathrm{C}$ and $5 \% \mathrm{CO}_{2}$ for $24 \mathrm{~h}$. The cell pellets were harvested through centrifugation at 20,387 $\times g$ for $10 \mathrm{~min}$. Subsequently, the cell pellets were washed twice with sterilized PBS before incubation with the FITC antimouse CD80 (Biolegend, San Diego, CA) at a final concentration of $0.025 \mathrm{mg} / \mathrm{mL}$ for $2 \mathrm{~h}$ at $4^{\circ} \mathrm{C}$ in the dark. Afterward, the cell pellets were washed twice with sterilized PBS and used for analysis by flow cytometer (EPICS XL; Beckman Coulter, Brea, CA). The expression of CD80 molecules was compared with the RAW264.7 macrophages treated without bacterial cells.

\section{RNA Extraction and Real-Time PCR}

The RAW264.7 cells were harvested and centrifuged at $20,387 \times g$ for $10 \mathrm{~min}$ at $4^{\circ} \mathrm{C}$, and the cell pellet was stored at $-80^{\circ} \mathrm{C}$. Extraction of RNA from the cell pellet was performed using a Qiashredder and RNeasy Mini Kit (Qiagen, Valencia, CA) according to the manufacturer's instructions. Total RNA was used for the cDNA synthesis using ReverTra Ace qPCR RT master mix (Toyobo Co. Ltd., Osaka, Japan). The procedures were conducted as described in the manufacturer's protocols. Primers for real-time PCR were designed using Primer Express 3.0 software (Applied Biosystems, Foster City, $\mathrm{CA}$ ), the reactions were prepared using Brilliant III Ultra Fast SYBR green qPCR master mix (Agilent Technologies, Santa Clara, CA), and the detection was performed using an Applied Biosystems StepOne real-time PCR system. The gene expression was calculated using the comparative cycle threshold $(\Delta \Delta \mathrm{CT})$ method. All samples were normalized based on the data using primers specific to the $\beta$-actin gene. The primers used for real-time PCR were as follows: mouse CD80 (Gene Bank accession no.), forward 5'-TCCATGTCCAAGGCTCATTC-3' and reverse 5'-TAACGGCAAGGCAGCAATA-3'; mouse $I L 1 B$, forward 5'-AGTTGACGGACCCCAAAA GA-3' and reverse 5'-GGACAGCCCAGGTCAAAGG-3'; mouse IL18, forward 5'-CTCCAGCATCAGGACAAAGAAA-3' and reverse 5'-GGCCAAGAGGAAGTGATTTGG-3'; and mouse $\beta$-actin, forward 5'-CTGAACCCTAAGGCCAACCGTG-3' and reverse 5'-GGCATACAGGGACAGCACAGCC- $3^{\prime}$.

\section{Preactivation Assay}

Briefly, RAW264.7 macrophages were coincubated with L. johnsonii NBRC 13952 at the MOI 5:1 at $37^{\circ} \mathrm{C}$ and $5 \% \mathrm{CO}_{2}$ for $24 \mathrm{~h}$. Subsequently, the supernatant was discarded and replaced with fresh $\alpha$-MEM containing viable $A$. actinomycetemcomitans Y4 cells to achieve MOI 50:1. The cell mixture was precipitated to the bottom of a 6 -well plate through centrifugation at $1,000 \times g$ for $10 \mathrm{~min}$ and incubated at $37^{\circ} \mathrm{C}$ and $5 \% \mathrm{CO}_{2}$ for $60 \mathrm{~min}$ to facilitate the phagocytosis activity by macrophage cells. Subsequently, the cells were washed thrice using $\alpha$-MEM supplemented with $200 \mu \mathrm{g} / \mathrm{mL}$ of gentamycin to remove the bacterial cells from the medium and then were replaced with fresh $\alpha$-MEM supplemented with $5 \%$ fetal blood serum and incubated for an additional 24 and $48 \mathrm{~h}$. After that, the cell pellets were centrifuged at $20,387 \times g$ for $10 \mathrm{~min}$, and the supernatant was collected after filtration using a $0.2-\mu \mathrm{m}$ membrane filter and preserved at $-80^{\circ} \mathrm{C}$ for further analysis. The remaining cell pellets were col- 
lected for the hypodiploid DNA (SubG1) analysis by flow cytometer.

\section{Analysis of SubG1}

The analysis of SubG1 was performed by using the cell pellet mentioned above. The pellets were washed twice in PBS and treated with propidium iodide (50 $\mu \mathrm{g} / \mathrm{mL})$ at $4^{\circ} \mathrm{C}$ for $30 \mathrm{~min}$. Subsequently, the level of SubG1 was analyzed using Epics XL (Beckman Coulter). The cycle phases were analyzed using Multicycle for Windows (Phoenix Flow Systems, San Diego, CA).

\section{Statistical Analysis}

Data represent the mean \pm standard deviation of at least 3 independent experiments. Comparisons were performed by the means of Student's $t$-test using GraphPad software (https://www.graphpad.com/quickcalcs/ ttest1/), and $P<0.05$ was considered significant.

\section{RESULTS}

\section{Enhanced Phagocytic Activity by Probiotic Lactobacilli}

Phagocytic activity is an important indicator of the activation of macrophage cells, which triggers the complex response for a host immune defense against the pathogenic bacteria. In this study, the classical activation to promote the killing effect against the periodontopathic bacterium A. actinomycetemcomitans Y4 was the main focus of our research.

The phagocytic activity of the macrophages triggered by probiotic lactobacilli might be effective to activate the immune cells. As shown in Figure 1, the phagocytic activity of RAW264.7 cells induced by the dead cells of lactic acid bacteria $($ LAB $)$ was significantly higher $(P$ $<0.001$ ) than that without LAB or with A. actinomycetemcomitans $\mathrm{Y} 4$ cells. The highest activity was shown in L. johnsonii NBRC 13952, followed by L. plantarum NBRC 15891 and L. fermentum NBRC 15885. On the other hand, the macrophages treated with dead A. actinomycetemcomitans Y4 cells showed lower phagocytic activity than those treated with dead LAB cells. The result suggests that the probiotic lactobacilli have a greater ability to activate the macrophages than $A$. actinomycetemcomitans Y4.

\section{Viability of the RAW264.7 Cells}

Next, the cell viability of RAW264.7 macrophage cells in the presence of each bacterial strain was evaluated using viable bacteria cells at the different MOI values
(500, 50, and 5). As shown in Figure 2A, the $3 \mathrm{LAB}$ strains had no or less cytotoxic effect on the RAW264.7 cells, although a moderate cytotoxic effect was shown in L. fermentum NBRC 15885 at the MOI values 500 and 50 , which had 55 and $41 \%$ of dead cells, respectively. The percentage of dead cells in $L$. fermentum NBRC 15885 was evaluated as a significant difference $(P<$ $0.05)$ compared with the untreated cells, whereas other LAB strains showed the same effect as untreated macrophage cells. Among the 3 LAB strains, L. johnsonii NBRC 13952 showed the least cytotoxic effect against the RAW264.7 macrophage cells. In contrast, viable A. actinomycetemcomitans Y4 cells showed the highest toxicity to the RAW264.7 cells (the percentage of dead cells was 77 and $94 \%$ at the MOI values 5 and 500, respectively) and highly significant difference compared with the untreated cells $(P<0.001)$.

The production of pro-IL-1 $\beta$ (31 kDa) and IL-1 $\beta$ (17 $\mathrm{kDa}$ ) from the RAW264.7 macrophage cells coincubated with $A$. actinomycetemcomitans Y4 or LAB was investigated using western blot. Interestingly, the active form of IL-1 $\beta$ was expressed only in the macrophage cells coincubated with $A$. actinomycetemcomitans Y4 cells. No active forms of IL- $1 \beta$ from the macrophages were coincubated with the probiotic lactobacilli (Figure $2 \mathrm{~B}$ ), suggesting that probiotic lactobacilli can activate macrophage cells without having to be cytotoxic to the cells.

In addition, the influence of probiotic lactobacilli and A. actinomycetemcomitans Y4 on the RAW264.7 cells was evaluated using a fluorescence staining method.

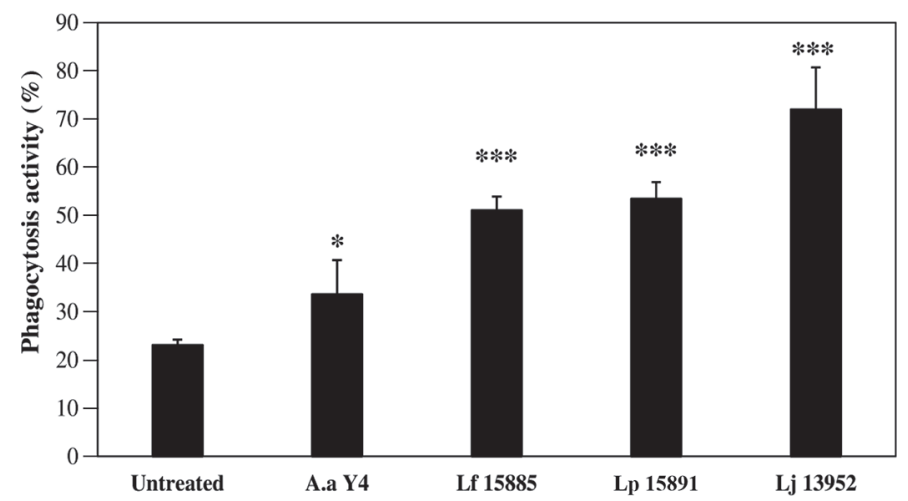

Figure 1. Phagocytic activity of RAW264.7 macrophages after a 24-h incubation with bacterial cells. The RAW264.7 macrophages were coincubated with Aggregatibacter actinomycetemcomitans Y4 (A.a Y4) or the probiotic strains Lactobacillus fermentum NBRC 15885 (Lf 15885), Lactobacillus plantarum NBRC 15891 (Lp 15891), and Lactobacillus johnsonii NBRC 13952 ( $\mathrm{Lj}$ 13952) at the multiplicity of infection value $1,000: 1$, and the mixture was used to evaluate the phagocytic activity using latex beads-rabbit IgG-fluorescein isothiocyanate. Bars represent the mean, error bars present the SD, and significance was measured using Student's $t$-test $\left({ }^{*} P<0.05\right.$, ${ }^{* * *} P<$ $0.001)$. 
(A)
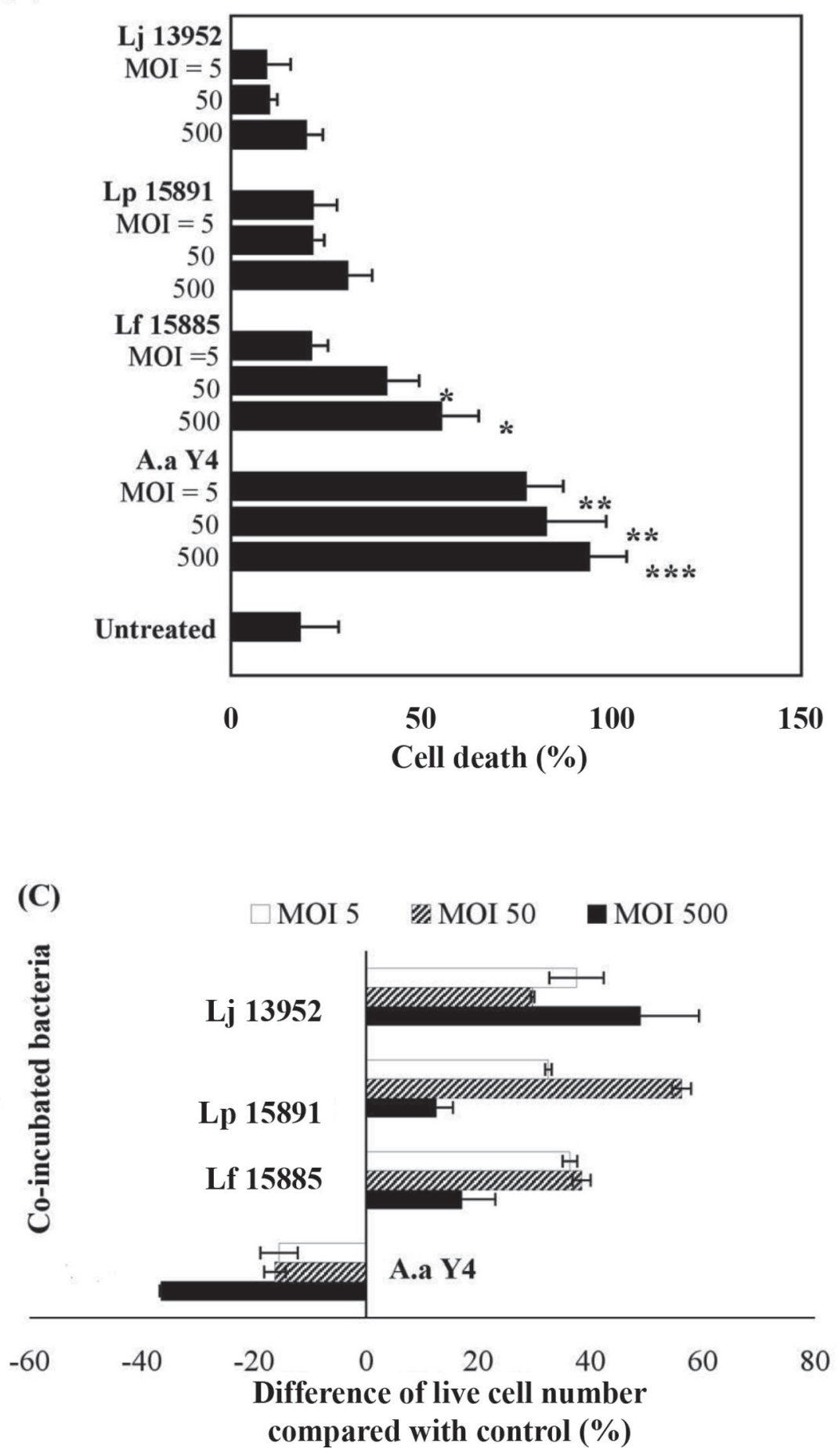

(B)
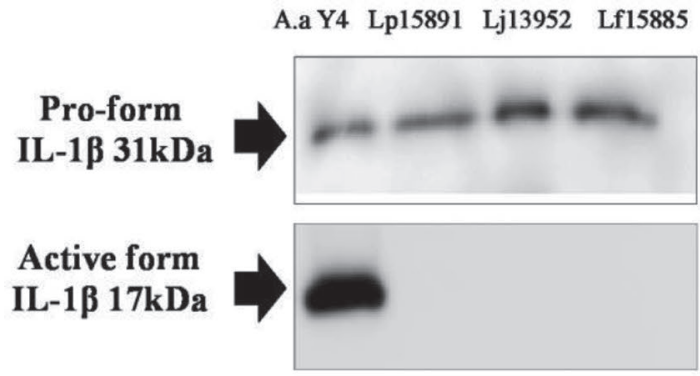

及-actin

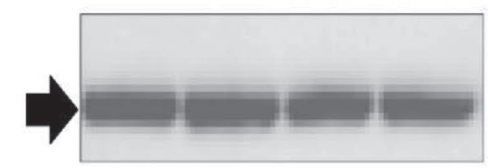

Figure 2. Viability of RAW264.7 macrophages after the infection of bacterial cells. (A) Initially, RAW264.7 macrophages were treated for 2 $\mathrm{h}$ with bacterial cells at the multiplicity of infection (MOI) values 500:1, 50:1, or 10:1. Then, the viability of RAW264.7 macrophages after the additional 18-h incubation was determined by the trypan blue exclusion method. (B) The production of IL-1 $\beta$ was detected by Western blotting for the supernatant of RAW264.7 macrophages coincubated with each bacterial cell at the MOI value 500:1. (C) The number of living RAW264.7 macrophage cells was evaluated after the incubation with probiotic lactobacilli ( $\mathrm{Lj} 13952$, Lp 15891, and Lf 15885) and a periodontal pathogen (A.a Y4) as the control. A.a Y4 = Aggregatibacter actinomycetemcomitans Y4; Lj $13952=$ Lactobacillus johnsonii NBRC 13952; Lp 15891 = Lactobacillus plantarum NBRC 15891; Lf 15885 = Lactobacillus fermentum NBRC 15885. Bars represent the mean, error bars present the SD, and significance was measured using Student's $t$-test $\left(* P<0.05,{ }^{* *} P<0.01,{ }^{* * *} P<0.001\right)$. 
Our results showed that the viability and proliferation of RAW264.7 cells was remarkably increased by the stimulation of LAB (Figure 2C). The number of viable RAW264.7 cells coincubated with LAB increased up to $50 \%$ compared with the untreated cells. This suggests that LAB promote the proliferation of macrophage cells. In contrast, for the macrophage cells coincubated with A. actinomycetemcomitans $\mathrm{Y} 4$, the number of viable cells observed decreased, indicating that the RAW264.7 cells were killed.

\section{M1 Markers Expressed by Activated Macrophages}

Lactobacillus johnsonii NBRC 13952 at the MOI value 5 had higher phagocytic activity $(P<0.001)$ than the control (untreated macrophage cells; Figure 3A). The expression of M1 markers (e.g., IL-1 $\beta$, IL-18, and CD80) was monitored to evaluate the activation of macrophage cells. As a result, the expression of IL-1 $\beta$ was significantly high (Figure 3B). In contrast, there was no significant difference in the expression of IL-18 (Figure 3C). On the other hand, the expression of CD80 molecules showed a significant increase in the presence of LAB (Figure 3D and E). Thus, the results that had a high phagocytic activity and a high expression of M1 markers may indicate that L. johnsonii NBRC 13952 functions to activate the RAW264.7 macrophage cells. A flow cytometer was used to reconfirm the expression of CD80 molecules, which are important indicators for the activation of macrophages. As shown in Figure 3E, the expression of CD80 molecules in the RAW264.7 cells was upregulated by the stimulation of $L$. johnsonii NBRC 13952.

\section{Enhanced Phagocytic Activity by Activated Macrophages Through the Stimulation of LAB}

Because L. johnsonii NBRC 13952 activated the macrophage cells, the activated macrophage may be useful for facilitating the uptake of A. actinomycetemcomitans Y4 cells. Thus, the phagocytic activity by the activated macrophage cells was evaluated by using $A$. actinomycetemcomitans Y4 cells. As shown in Figure 4, phagocytic activity to A. actinomycetemcomitans Y4 cells remarkably increased by the pretreatment with $L$. johnsonii NBRC $13952(P<0.001)$ compared with the pretreatment with only A. actinomycetemcomitans Y4 or L. johnsonii NBRC 13952.

Furthermore, apoptotic activity was evaluated during the phagocytosis to A. actinomycetemcomitans cells by activated macrophage cells. The apoptotic activity was determined by measuring the amount of SubG1 of the RAW264.7 macrophages using a flow cytometer. Activated RAW267.4 cells had a significantly high amount of SubG1 $(P<0.001)$ compared with the control macrophages treated with $A$. actinomycetemcomitans $\mathrm{Y} 4$, whereas the macrophages without the pretreatment had slower apoptotic activity (Figure 5). The results indicate that the activated RAW264.7 macrophage cells by L. johnsonii NBRC 13952 not only enhanced phagocytic activity but also increased apoptotic activity to efficiently kill the cells of A. actinomycetemcomitans $\mathrm{Y} 4$.

\section{DISCUSSION}

In this study, we demonstrated the effect of probiotic lactobacilli in the phagocytic activity by macrophage cells to combat the cells of $A$. actinomycetemcomitans. Probiotic lactobacilli are highlighted to have not only antimicrobial activity (Das and Goyal, 2014; Pieniz et al., 2014; Shokryazdan et al., 2014) but also immunomodulation capacity (Kapila et al., 2012; Jang et al., 2013; Christoffersen et al., 2014; Maldonado Galdeano, 2015). In our recent report, the probiotic lactobacilli had a high ability to degrade a mature biofilm of $A$. actinomycetemcomitans (Jaffar et al., 2016a). Basically, A. actinomycetemcomitans is a significant periodontal pathogen that is associated with aggressive juvenile periodontitis (Åberg et al., 2015). Aggregatibacter actinomycetemcomitans produces immunosuppressive factors (Shenker et al., 1999), inhibits phagocytosis activity and the production of cytokines (Ando-Suguimoto et al., 2014), and promotes apoptosis of the macrophage (Kato et al., 1995; Okinaga et al., 2007, 2013). Thus, A. actinomycetemcomitans $\mathrm{Y} 4$ as an infection source is important for evaluating the effectiveness of the RAW264.7 cells activated by probiotic lactobacilli.

A primary function of macrophages is to phagocytize and degrade invading pathogens (Zhang and Wang, 2014). However, weakened phagocytosis might occur due to the lack of a key phagocytic component to increase the susceptibility to bacterial infection (Yuste et al., 2006). An important step for the immunomodulation by probiotic lactobacilli is to see the ability to enhance phagocytic activity by the RAW264.7 cells. Our results showed that the phagocytosis of activated RAW264.7 macrophages was significantly stimulated and that the activation of the macrophages was different between the probiotic lactobacilli species tested. The result is comparable with a previous study that demonstrated the ability of Lactobacillus casei CRL 431 and Lactobacillus paracasei CNCM 1-1518 to activate macrophages and to improve a host response against infection with Salmonella Typhimurium (Maldonado Galdeano, 2015). In addition, one study showed that the oral uptake of probiotic lactobacilli (Lactobacillus acidophilus, L. casei, and Lactobacillus helveticus) 
(A)

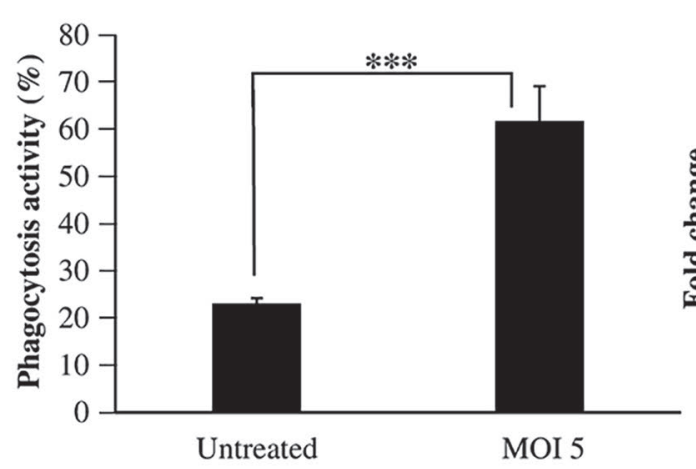

(C)

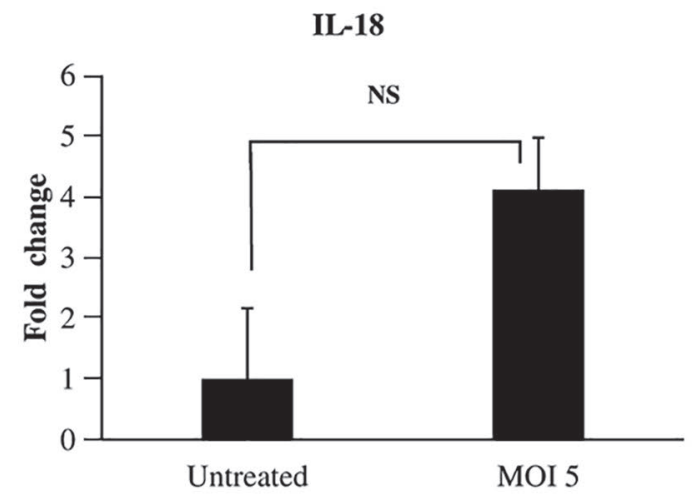

(E)

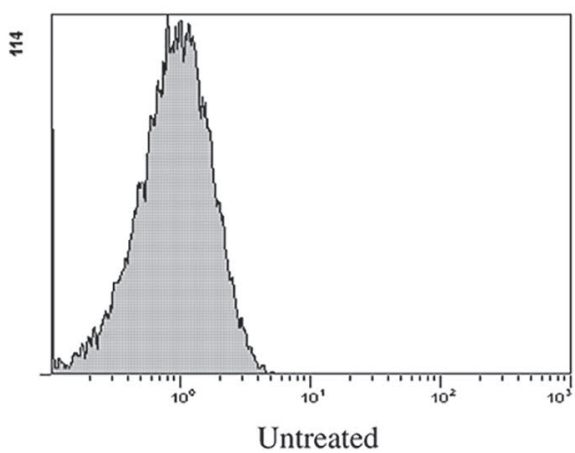

(B)

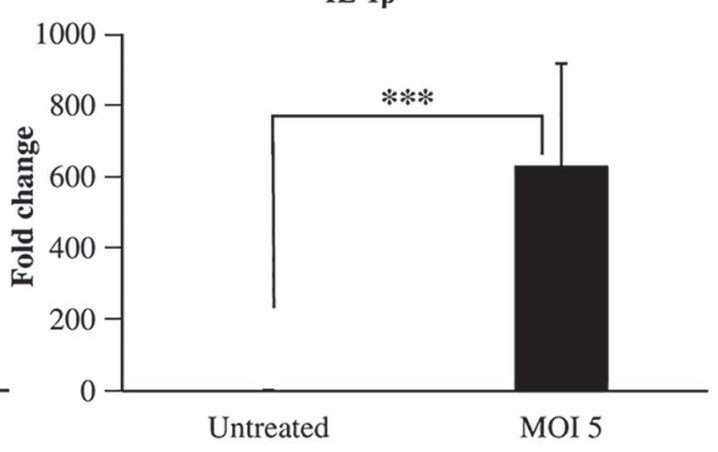

(D)

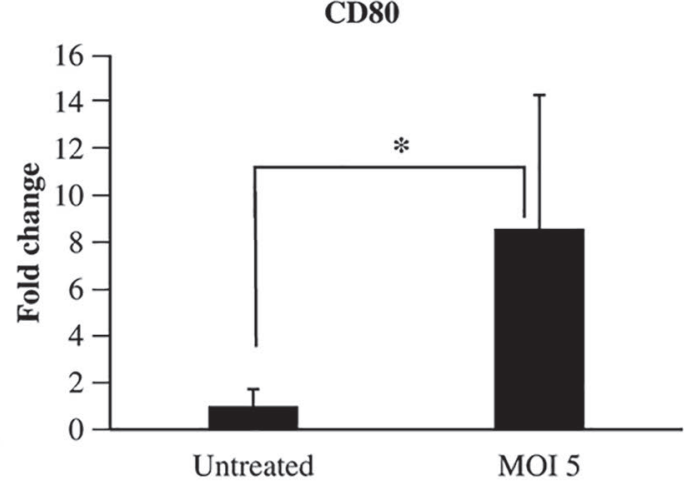

(F3)(Ungated] 20012914.Imd : FL1 LOG

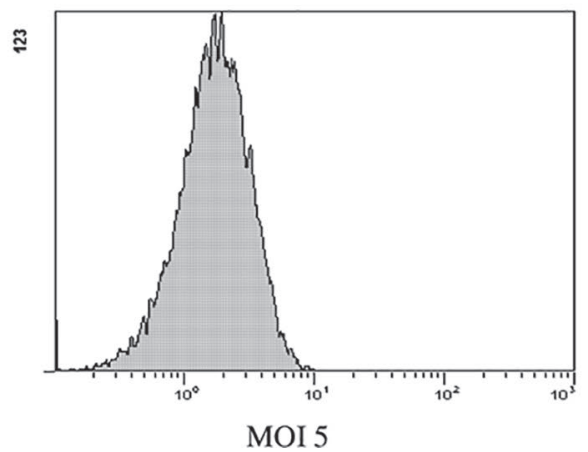

Figure 3. Phagocytic activity and the production of M1 markers by the RAW264.7 macrophage cells with or without incubation with Lactobacillus johnsonii NBRC 13952 at the multiplicity of infection (MOI) value 5:1. (A) Phagocytic activity, (B) IL-1及, (C) IL-18, and (D, E) the expression of CD80 molecules by real-time PCR and flow cytometer analysis. Bars represent the mean, error bars present the SD, and significance was measured using Student's $t$-test $\left({ }^{*} P<0.05,{ }^{* * *} P<0.001\right)$. NS $=$ no significant difference.

triggered a significant increase of phagocytic activity (Kapila et al., 2012). Activated macrophages might function to kill microbes (classical activation), produce extracellular matrix components for the promotion of wound healing (alternative activation), or secrete antiinflammatory cytokines to terminate the inflammation (regulatory macrophages; Mosser and Zhang, 2008)
All 3 LAB strains used in this study were found to induce a proliferation of RAW264.7 macrophage cells. The ability of the LAB strains to induce macrophage proliferation has been reported in a previous study that mentioned a significant increase of macrophage viability in the J774.1 murine macrophages coincubated with Lactobacillus rhamnosus before and after infection with 


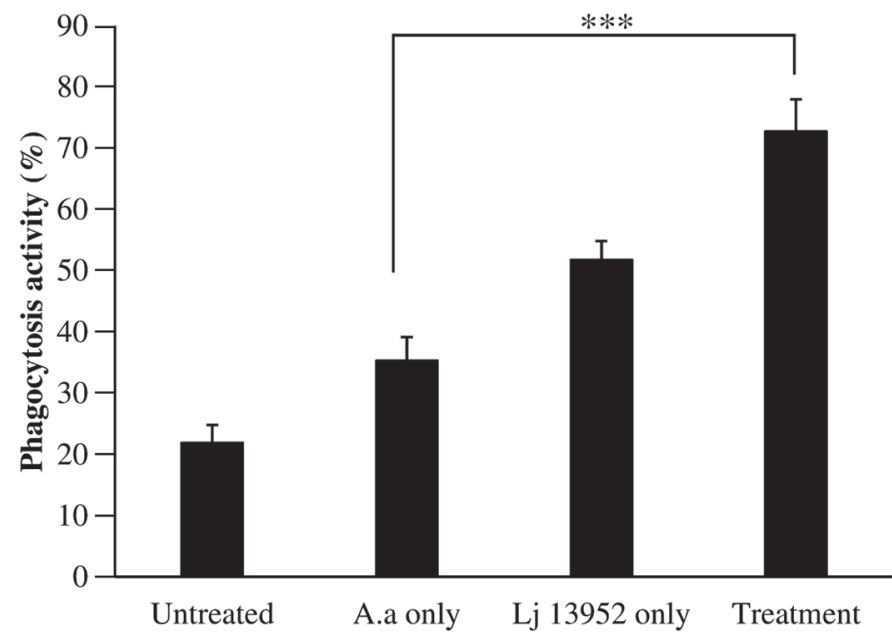

Figure 4. Enhanced phagocytic activity of RAW264.7 macrophages by incubation with bacterial cells. The phagocytic activity of RAW264.7 macrophages was determined after incubation with Aggregatibacter actinomycetemcomitans Y4 only (A.a), incubation with Lactobacillus johnsonii NBRC 13952 only (Lj 13952), or preincubation with L. johnsonii NBRC 13952 followed by a 2-h incubation with A. actinomycetemcomitans Y4 cells (Treatment; multiplicity of infection value 50). As a control, RAW264.7 macrophage cells without any bacterial cells were used (Untreated). Bars represent the means, error bars represent the SD, and significance was measured using Student's $t$-test $(* * * P<0.001)$.

herpes simplex virus type 1 (Khani et al., 2012). Cell lysates from $L$. plantarum were also found to induce the proliferation of immune splenocytes and Peyer's patch

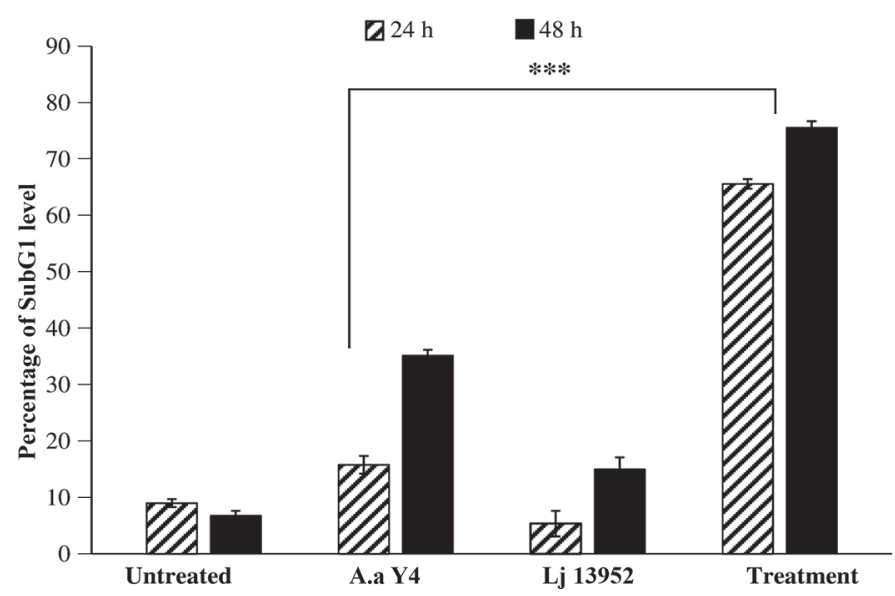

Figure 5. Comparison of the hypodiploid DNA (SubG1) amount (apoptotic activity) of RAW264.7 macrophages after 24 and $48 \mathrm{~h}$ of incubation with bacterial cells. The amount of SubG1 was detected from the macrophage cells after incubation with Aggregatibacter actinomycetemcomitans Y4 only (A.a Y4), incubation with Lactobacillus johnsonii NBRC 13952 only ( $\mathrm{Lj}$ 13952), or preincubation with L. johnsonii NBRC 13952 followed by a 2-h incubation with A. actinomycetemcomitans Y4 cells (Treatment). As a control, RAW264.7 macrophage cells without any bacterial cells were used (Untreated). Bars represent the means, error bars represent the $\mathrm{SD}$, and significance was measured using Student's $t$-test $(* * * P<0.001)$. cells and to enhance the production of nitric oxide by the peritoneal macrophages (Chae et al., 1998).

The activation of macrophages that coincubated with L. johnsonii NBRC 13952 was determined by the expression of M1 markers, IL-13, IL-18, and CD80. Probiotic bacteria have been reported to have a role in diminishing the proinflammatory activity through enhancing the production of IL-10 (Jang et al., 2013; Rong et al., 2015 ) and inhibiting the expression of IL- $1 \beta$, TNF- $\alpha$, and IL-6 (Jang et al., 2013). However, in this study, we found that one of the probiotic lactobacilli, L. johnsonii NBRC 13952, has a role in inducing the proinflammatory response by upregulating the expression of IL-1 $\beta$ and CD80. A high amount of IL-1 $\beta$ and CD-80 may trigger the activation of M1 macrophages, which is an important response for an infection (Benoit et al., 2007; Mosser and Zhang, 2008; Lopez-Castejon and Brough, 2011). In addition, an increased expression of IL-1 $\beta$ was observed in the activated RAW264.7 cells with LAB, although the viability of the macrophages was not affected. The result might be due to the precursor of IL-1 $1 \beta$, which is inactive and requires a proinflammatory protease, caspase-1 (Thornberry et al., 1992), to be an active form (Lopez-Castejon and Brough, 2011), and subsequent proinflammatory activities (Åberg et al., $2015)$. The production of pro-IL-1 $\beta$ might be stimulated by any molecule produced from bacterial cells (e.g., lipopolysaccharide), and the production of the active form, IL-1 $\beta$ (17 kDa) might be due to the endogenous molecules from dead macrophages, which can induce the secretion of active IL-1 $\beta$ (Lopez-Castejon and Brough, 2011). The activation of M1 macrophages was also reported in a previous study using Bacillus amyloliquefaciens, demonstrating a significant expression of IL-1 $\beta$, inducible nitric oxide synthase, TNF- $\alpha$, and IL-6 (Ji et al., 2013). In addition, another study showed that L. rhamnosus strains GG and LC705 induced the production of IL-1 $\beta$ in the human macrophages through the activation of caspase-1, thereby increasing inflammasome activity for the infection by influenza A virus (Miettinen et al., 2012).

Aggregatibacter actinomycetemcomitans Y4 cells are cytotoxic against macrophages by promoting the apoptosis of the cells (Kato et al., 1995). Because the induction of apoptotic activity was inhibited by cytochalasin $\mathrm{D}$, the uptake of $A$. actinomycetemcomitans cells inside the macrophage cells should be a key event for the cytotoxicity and apoptosis trigged by the cells (Kato et al., 1995). Hence, the infection of A. actinomycetemcomitans Y4 in the activated RAW264.7 macrophages may stimulate not only a large amount of IL- $1 \beta$ production (Okinaga et al., 2015) but also the production of inflammasome complex (Åberg et al., 2015), caspase-1, and caspase-3 (Nonaka et al., 2001), resulting in the 
apoptotic cell death of macrophages. Conceptually, the RAW264.7 macrophage cells preactivated by $L$. johnsonii NBRC 13952 might make an active mode of macrophage by inducing the A. actinomycetemcomitans-infected macrophage cells to apoptosis. In addition, a high expression of IL-1 $\beta$ may correlate with high phagocytic activity induced by L. johnsonii NBRC 13952. Apoptotic cell nuclei are often fragmented, and several chromatin fragments are released from a single apoptotic cell and able to be detected by a flow cytometer as an object characterized by SubG1 content. The incorporated $A$. actinomycetemcomitans Y4 cells by the activated macrophages were assumed to be killed when the macrophage cells died via apoptosis (Schaechter et al., 2013), resulting in a high amount of SubG1. This might be an important pathway for the clearance of A. actinomycetemcomitans cells inside the macrophage cells. On the other hand, the internalized A. actinomycetemcomitans $\mathrm{Y} 4$ cells by the macrophages without the stimulation by L. johnsonii NBRC 13952 may have more time to clean the cells (DeLeo, 2004), resulting in delayed apoptosis, which had a lower amount of SubG1. A previous study documents that different cytokines such as TNF- $\alpha$, IL-1 $\beta$, granulocyte macrophage colonystimulating factor, and transforming growth factor $\beta 1$ are able to promote phagocytic activity (Sharma et al., 2014).

\section{CONCLUSIONS}

Aggregatibacter actinomycetemcomitans is reported to be pathogenic to humans, and this microbe is also found to cause infection in animals. Counteraction of bacterial infection using antibiotic administration has shown a resistance issue, which might affect animal growth and milk production. This study showed a potential role triggered by probiotic lactobacilli to counteract the infection. Probiotic lactobacilli used in this study might promote an active mode of the macrophages without killing the phagocytic cells. In addition, this study is important for understanding a counteraction mechanism of probiotic lactobacilli against an infection of highly adaptive pathogens by modulating the innate immune response. This may initiate or motivate the supplementation of probiotic bacteria in dairy animals as a nonchemical approach against an infection.

\section{ACKNOWLEDGMENTS}

This research was supported by the Pfizer Health Research Foundation (Tokyo, Japan). N. J. received a scholarship from the University of Sultan Zainal Abidin (Kuala Terengganu, Terengganu Darul Iman, Malay- sia). The funders had no role in the study design, data collection and analysis, decision to publish, or preparation of the manuscript.

\section{REFERENCES}

Åberg, C. H., P. Kelk, and A. Johansson. 2015. Aggregatibacter actinomycetemcomitans: Virulence of its leukotoxin and association with aggressive periodontitis. Virulence 6:188-195. https://doi.org/10 $.4161 / 21505594.2014 .982428$.

Ando-Suguimoto, E. S., M. P. Da Silva, D. Kawamoto, C. Chen, J. M. DiRienzo, and M. P. A. Mayer. 2014. The cytolethal distending toxin of Aggregatibacter actinomycetemcomitans inhibits macrophage phagocytosis and subverts cytokine production. Cytokine 66:46-53. https://doi.org/10.1016/j.cyto.2013.12.014.

Benoit, M., F. Fenollar, D. Raoult, and J. L. Mege. 2007. Increased levels of circulating IL-16 and apoptosis markers are related to the activity of Whipple's disease. PLoS One 2:e494. https://doi.org/ 10.1371/journal.pone.0000494.

Chae, O., K. Shin, and H. T. C. Chung. 1998. Immunostimulation effects of mice fed with cell lysate of Lactobacillus plantarum isolated from kimchi. KSBB J. 13:424-430.

Christoffersen, T. E., L. T. O. Hult, K. Kuczkowska, K. M. Moe, S. Skeie, T. Lea, and C. R. Kleiveland. 2014. In vitro comparison of the effects of probiotic, commensal and pathogenic strains on macrophage polarization. Probiotics Antimicrob. Proteins 6:1-10. https://doi.org/10.1007/s12602-013-9152-0.

Cohen, J. 2002. The immunopathogenesis of sepsis. Nature 420:885891. https://doi.org/10.1038/nature01326.

Das, D., and A. Goyal. 2014. Characterization and biocompatibility of glucan: A safe food additive from probiotic Lactobacillus plantarum DM5. J. Sci. Food Agric. 94:683-690. https://doi.org/10 $.1002 /$ jsfa. 6305 .

DeLeo, F. R. 2004. Modulation of phagocyte apoptosis by bacterial pathogens. Apoptosis 9:399-413. https://doi.org/10.1023/B: APPT.0000031448.64969.fa.

Jaffar, N., Y. Ishikawa, K. Mizuno, T. Okinaga, and T. Maeda. 2016a. Mature biofilm degradation by potential probiotics: Aggregatibacter actinomycetemcomitans versus Lactobacillus spp. PLoS One 11:e0159466. https://doi.org/10.1371/journal.pone.0159466.

Jaffar, N., T. Miyazaki, and T. Maeda. 2016b. Biofilm formation of periodontal pathogens on hydroxyapatite surfaces: Implications for periodontium damage. J. Biomed. Mater. Res. A 104:2873-2880. https://doi.org/10.1002/jbm.a.35827.

Jang, S. E., M. J. Han, S. Y. Kim, and D. H. Kim. 2014. Lactobacillus plantarum CLP-0611 ameliorates colitis in mice by polarizing M1 to M2-like macrophages. Int. Immunopharmacol. 21:186-192. https://doi.org/10.1016/j.intimp.2014.04.021.

Jang, S. E., S. R. Hyam, M. J. Han, S. Y. Kim, B. G. Lee, and D. H. Kim. 2013. Lactobacillus brevis G-101 ameliorates colitis in mice by inhibiting NF-KB, MAPK and AKT pathways and by polarizing M1 macrophages to M2-like macrophages. J. Appl. Microbiol. 115:888-896. https://doi.org/10.1111/jam.12273.

Ji, J., S. L. Hu, Z. W. Cui, and W. F. Li. 2013. Probiotic Bacillus amyloliquefaciens mediate M1 macrophage polarization in mouse bone marrow-derived macrophages. Arch. Microbiol. 195:349-356. https://doi.org/10.1007/s00203-013-0877-7.

Kapila, R., S. Kapila, M. Kapasiya, D. Pandey, A. Dang, and V. Saliganti. 2012. Comparative evaluation of oral administration of probiotic lactobacilli-fermented milks on macrophage function. Probiotics Antimicrob. Proteins 4:173-179. https://doi.org/10 $.1007 / \mathrm{s} 12602-012-9107-\mathrm{x}$.

Kasai, H., K. Nakashima, M. Yokota, and T. Nishihara. 2010. The G1 cell cycle arrest of macrophages infected with Aggregatibacter actinomycetemcomitans. Oral Dis. 16:305-309. https://doi.org/10 .1111/j.1601-0825.2010.01667.x.

Kato, S., M. Muro, S. Akifusa, N. Hanada, I. Semba, T. Fujii, Y. Kowashi, and T. Nishihara. 1995. Evidence for apoptosis of murine 
macrophages by Actinobacillus actinomycetemcomitans infection. Infect. Immun. 63:3914-3919.

Khani, S., M. Motamedifar, H. Golmoghaddam, H. M. Hosseini, and Z. Hashemizadeh. 2012. In vitro study of the effect of a probiotic bacterium Lactobacillus rhamnosus against herpes simplex virus type 1. Braz. J. Infect. Dis. 16:129-135. https://doi.org/10.1016/ S1413-8670(12)70293-3.

Li, X., K. M. Kolltveit, L. Tronstad, and I. Olsen. 2000. Systemic diseases caused by oral infection. Clin. Microbiol. Rev. 13:547-558.

Lopez-Castejon, G., and D. Brough. 2011. Understanding the mechanism of IL-1B secretion. Cytokine Growth Factor Rev. 22:189-195. https://doi.org/10.1016/j.cytogfr.2011.10.001.

Maldonado Galdeano, C. 2015. Stimulation of innate immune cells induced by probiotics: Participation of toll-like receptors. J. Clin. Cell. Immunol. 6:1-9. https://doi.org/10.4172/2155-9899.1000283.

Meyer, D. H., J. E. Lippmann, and P. M. Fives-Taylor. 1996. Invasion of epithelial cells by Actinobacillus actinomycetemcomitans: A dynamic, multistep process. Infect. Immun. 64:2988-2997.

Miettinen, M., T. E. Pietilä, R. A. Kekkonen, M. Kankainen, S. Latvala, J. Pirhonen, P. Österlund, R. Korpela, and I. Julkunen. 2012. Nonpathogenic Lactobacillus rhamnosus activates the inflammasome and antiviral responses in human macrophages. Gut Microbes 3:510-522. https://doi.org/10.4161/gmic.21736.

Morita, H., F. He, T. Fuse, A. C. Ouwehand, H. Hashimoto, M. Hosoda, K. Mizumachi, and J.-I. Kurisaki. 2002. Cytokine production by the murine macrophage cell line J774.1 after exposure to lactobacilli. Biosci. Biotechnol. Biochem. 66:1963-1966. https://doi .org/10.1271/bbb.66.1963.

Mosser, D. M., and X. Zhang. 2008. Activation of Murine Macrophages. Wiley, Hoboken, NJ.

Murray, P. J., and T. A. Wynn. 2011. Protective and pathogenic functions of macrophage subsets. Nat. Rev. Immunol. 11:723-737. https://doi.org/10.1038/nri3073.

Nonaka, K., A. Ishisaki, N. Okahashi, T. Koseki, S. Kato, M. Muro, K. Nakashima, T. Nishihara, and Y. Kowashi. 2001. Involvement of caspases in apoptotic cell death of murine macrophages infected with Actinobacillus actinomycetemcomitans. J. Periodontal Res. 36:40-47. https://doi.org/10.1034/j.1600-0765.2001.00613.x.

Oelschlaeger, T. A. 2010. Mechanisms of probiotic actions-A review. Int. J. Med. Microbiol. 300:57-62. https://doi.org/10.1016/j.ijmm 2009.08.005

Okinaga, T., W. Ariyoshi, S. Akifusa, and T. Nishihara. 2013. Essential role of JAK/STAT pathway in the induction of cell cycle arrest in macrophages infected with periodontopathic bacterium $\mathrm{Ag}$ gregatibacter actinomycetemcomitans. Med. Microbiol. Immunol. (Berl.) 202:167-174. https://doi.org/10.1007/s00430-012-0282-x.

Okinaga, T., W. Ariyoshi, and T. Nishihara. 2015. Aggregatibacter actinomycetemcomitans invasion induces interleukin- $1 \beta$ production through reactive oxygen species and cathepsin B. J. Interferon Cytokine Res. 35:431-440. https://doi.org/10.1089/jir.2014.0127.

Okinaga, T., H. Kasai, T. Tsujisawa, and T. Nishihara. 2007. Role of caspases in cleavage of lamin $\mathrm{A} / \mathrm{C}$ and PARP during apoptosis in macrophages infected with a periodontopathic bacterium. J. Med. Microbiol. 56:1399-1404. https://doi.org/10.1099/jmm.0.47193-0.

Pieniz, S., R. Andreazza, T. Anghinoni, F. Camargo, and A. Brandelli. 2014. Probiotic potential, antimicrobial and antioxidant activities of Enterococcus durans strain LAB18s. Food Control 37:251-256. https://doi.org/10.1016/j.foodcont.2013.09.055.

Rong, J., H. Zheng, M. Liu, X. Hu, T. Wang, X. Zhang, F. Jin, and L. Wang. 2015. Probiotic and anti-inflammatory attributes of an isolate Lactobacillus helveticus NS8 from Mongolian fermented koumiss. BMC Microbiol. 15:196. https://doi.org/10.1186/s12866 $-015-0525-2$

Sakaguchi, R., and J. Powers. 2012. Craig's Restorative Dental Materials. Elsevier Health Sciences, Amsterdam, the Netherlands.

Schaechter, M., N. C. Engleberg, V. J. DiRita, and T. Dermody. 2013. Schaechter's Mechanisms of Microbial Disease. Wolters Kluwer Health/Lippincott Williams \& Wilkins, Philadelphia, PA.

Sharma, L., W. Wu, S. L. Dholakiya, S. Gorasiya, J. Wu, R. Sitapara, V. Patel, M. Wang, M. Zur, S. Reddy, N. Siegelaub, K. Bamba, F. A. Barile, and L. L. Mantell. 2014. Assessment of phagocytic activity of cultured macrophages using fluorescence microscopy and flow cytometry. Methods Mol. Biol. 1172:137-145. https://doi .org/10.1007/978-1-4939-0928-5_12.

Shenker, B. J., T. Mckay, and S. Datar. 1999. Actinobacillus actinomycetemcomitans immunosuppressive protein is a member of the family of cytolethal distending toxins capable of causing a G2 arrest in human T cells. J. Immunol. 162:4773-4780. https://doi.org/10 .4049/jimmunol.166.11.6555.

Shokryazdan, P., C. C. Sieo, R. Kalavathy, J. B. Liang, N. B. Alitheen, M. Faseleh Jahromi, and Y. W. Ho. 2014. Probiotic potential of Lactobacillus strains with antimicrobial activity against some human pathogenic strains. BioMed Res. Int. 2014:927268. https:// doi.org/10.1155/2014/927268.

Silva, N., L. Abusleme, D. Bravo, N. Dutzan, J. Garcia-Sesnich, R. Vernal, M. Hernández, and J. Gamonal. 2015. Host response mechanisms in periodontal diseases. J. Appl. Oral Sci. 23:329-355. https://doi.org/10.1590/1678-775720140259.

Thornberry, N. A., H. G. Bull, J. R. Calaycay, K. T. Chapman, A. D. Howard, M. J. Kostura, D. K. Miller, S. M. Molineaux, J. R. Weidner, J. Aunins, K. O. Elliston, J. M. Ayala, F. J. Casano, J. Chin, G. J.-F. Ding, L. A. Egger, E. P. Gaffney, G. Limjuco, O. C. Palyha, S. M. Raju, A. M. Rolando, J. P. Salley, T.-T. Yamin, T. D. Lee, J. E. Shively, M. MacCross, R. A. Mumford, J. A. Schmidt, and M. J. Tocci. 1992. A novel heterodimeric cysteine protease is required for interleukin-1 beta processing in monocytes. Nature 356:768-774. https://doi.org/10.1038/356768a0.

Yuste, J., S. Ali, S. Sriskandan, C. Hyams, M. Botto, and J. S. Brown. 2006. Roles of the alternative complement pathway and $\mathrm{C} 1 \mathrm{q}$ during innate immunity to Streptococcus pyogenes. J. Immunol. 176:6112-6120. https://doi.org/10.4049/jimmunol.176.10.6112.

Zhang, L., and C. C. Wang. 2014. Inflammatory response of macrophages in infection. Hepatobiliary Pancreat. Dis. Int. 13:138-152. https://doi.org/10.1016/s1499-3872(14)60024-2. 